ANUARIO DE Estudios MEDIEVALES

45/2, julio-diciembre de 2015, pp. 881-914

ISSN 0066-5061

doi:10.3989/aem.2015.45.2.09

\title{
PODER Y CENTROS DE REPRESENTACIÓN: CASTROS Y CASTILLOS EN LA TOSCANA Y TIERRA DE CAMPOS (SIGLOS X-XII) ${ }^{1}$
}

\author{
POWER AND REPRESENTATION CENTRES: \\ CASTRA AND CASTLES IN TOSCANA \\ AND TIERRA DE CAMPOS (10TH-12TH CENTURIES)
}

\author{
MARÍA PÉREZ RODRÍGUEZ \\ Universidad de Salamanca
}

Resumen: Desde que Pierre Toubert publicara su estudio sobre el Lazio, el incastellamento se convirtió en un importante punto de partida a la hora de explicar el feudalismo en buena parte del mundo mediterráneo. Lejos de intentar validar su viabilidad en la Península Ibérica, se ha llevado a cabo un estudio sobre el papel ejercido por las fortificaciones y la naturaleza de los vínculos entre monarquía y aristocracias en la región de la Toscana y la ribera del Cea, en Tierra de Campos. El objetivo principal es observar las semejanzas y diferencias existentes entre ambas zonas y su incidencia en el desarrollo del feudalismo.

\begin{abstract}
Since Toubert published his research on Lazio, the concept of incastellamento has become an important starting point to explain Feudalism in good part of Medieval Mediterranean Europe. Far from to trying to validate the viability of this explanatory model for the Iberian Peninsula, we have conducted an analysis of the role of fortresses and the nature of bonds between monarchy and the aristocracies from the Toscana and the Cea's bank, in the Tierra de Campos region. Our main purpose is to observe the existence of similarities and differences between both areas and their incidence in the development of Feudal logics.
\end{abstract}

${ }^{1}$ Abreviaturas utilizadas: CDCA-I = Cavero Domínguez, Gregoria; Martín López, Encarnación, Colección documental del Archivo de la Catedral de Astorga. Vol. I; CDCA-II = Cavero Domínguez, Gregoria; Martín López, Encarnación, Colección documental del Archivo de la Catedral de Astorga. Vol. II; CDCL-III = Ruiz Asencio, José Manuel, Colección documental del Archivo de la Catedral de León. Vol. III; CDCO = García Larragueta, Santos, Colección de documentos de la Catedral de Oviedo; CDME = Ruiz Asencio, José Manuel; Ruiz Albi, Irene, Colección documental del Monasterio de San Pedro de Eslonza. Vol. I; CDMG-I = Burón Castro, Taurino, Colección documental del Monasterio de Gradefes. Vol. I; CDMS-(ss. IX-X) = Mínguez Fernández, José María, Colección diplomática del Monasterio de Sahagún. Siglos $I X-X$; CDMS-II = Herrero de la Fuente, Marta, Colección diplomática del Monasterio de Sahagún. Vol.II; CDMS-III = Herrero de la Fuente, Marta, Colección diplomática del Monasterio de Sahagún. Vol. III; CDMS-IV = Fernández Flórez, José Antonio, Colección diplomática del Monasterio de Sahagún. Vol. IV. CDMV = Domínguez Sánchez, Santiago, Colección documental medieval de los monasterios de San Claudio de León, Monasterio de Vega y San Pedro de las Dueñas. Alfonso VI = Gambra, Andrés, Alfonso VI. Cancillería, curia e imperio. Vol. II. Este trabajo se ha realizado gracias al apoyo de una Beca de Personal de Investigación en Formación concedida por la Junta de Castilla y León y el Fondo Social Europeo. 
Palabras clave: incastellamento; fortificaciones; poder central; aristocracias; feudalismo.
Keywords: incastellamento; fortresses; central power; aristocracies; feudalism.

\section{SUMARIO}

0. Introducción.- 1. El caso italiano. Los núcleos "incastellados" en su dimensión política, social y económica.- 1.1. Juego de poderes: ¿implicación de la autoridad central?.- 2. Centros de poder y poderes en Tierra de Campos. La ribera del Cea.2.1. Los castros y la jerarquización territorial.- 2.2. Reestructuración administrativoterritorial: la respuesta regia.- 2.3. Castros y castillos: el papel de los núcleos fortificados.- 3. Conclusiones.- 4. Bibliografía citada.

\section{INTRODUCCIÓN}

A raíz de la obra de Toubert ${ }^{2}$, publicada hace casi 40 años, el incastellamento se convirtió en un importante punto de referencia para quienes pretendían abordar el estudio del desarrollo feudal europeo. Sin descartar el enorme peso alcanzado por la misma, hay que reconocer que el significado atribuido a semejante concepto ha ido -o debería haberlo hecho- evolucionando a lo largo del tiempo acorde a las transformaciones experimentadas por otros términos no menos significativos, tales como castrum o castellum, y a la propia evolución historiográfica.

Desde el primero de estos puntos de vista, hemos de advertir que el estudio del castro y del castillo no resulta novedoso, habiendo sido éste abordado desde multitud de líneas de investigación. Partiendo de aquellos postulados que ponían su acento en el carácter eminentemente militar y estratégico de tales estructuras, hasta la definición que de los mismos nos ofrecen autores como Francovich y Ginatempo o Wickham ${ }^{3}$. Sin pretender realizar un análisis exhaustivo de tal progresión historiográfica, cabe al menos señalar las aportaciones que desde las primeras décadas del siglo $\mathrm{XX}$ nos proporcionan autores como Luzzato y Plesner, Pertile, Gabotto, Volpe o el propio Toubert, para quien la fundación castral quedaba asociada, por un lado, a la concentration du peuplement $\mathrm{y}$, por otro, al reagrupement parallèle des terroirs en finages ${ }^{4}$.

\footnotetext{
${ }^{2}$ Toubert 1973.

${ }^{3}$ Francovich y Ginatempo comparten la concepción del castillo como lugar arqueológico privilegiado a la hora de estudiar los asentamientos rurales y en el que poder leer las formas de poder y las bases económicas de la vida social a través de los indicadores materiales, técnicas de construcción y tecnología productiva. Véase Francovich, Ginatempo 2000, p. 7. Por otro lado, para Wickham el castillo facilita la comprensión del contenido de los cambios sociales. Véase Wickham 1998,p. 31.

${ }^{4}$ Toubert 1973, p. 349.
} 
A nivel historiográfico, y coincidiendo con lo que Mínguez ha dado en considerar como una década especialmente fructífera para el conocimiento de la sociedad occidental altomedieval ${ }^{5}$, la multiplicación de aspectos y líneas interpretativas desde las que abordar el análisis del feudalismo, puede ser contemplada como el resultado de las transformaciones que desde los años $70 \mathrm{y}$ 80 viene experimentando la historiografía; renovación que podríamos estimar, además, aplicable al método arqueológico.

Es en este contexto de renovación en el que hemos de insertar aspectos como el poblamiento rural y los modelos de articulación territorial, el desarrollo de los poderes aristocráticos, su manifestación material y las bases de su relación con el poder central, convirtiéndose todos ellos en los nuevos ejes de articulación del debate historiográfico y elementos esenciales a tener en cuenta a la hora de comprender el incastellamento.

No obstante, la aparición y posterior divulgación de este término -que había llegado a convertirse en modelo explicativo del desarrollo feudal- dio origen a la evidente reacción por parte de numerosos estudiosos que, sin dejar de reconocer la importancia del mismo, comenzaron a dudar de su posible e incuestionable aplicación a la totalidad del Occidente medieval. El hecho se encontraba, efectivamente, en relación directa al elevado grado de heterogeneidad que caracteriza el desarrollo del proceso. En el caso concreto de la Península Ibérica, Mínguez ha insistido en la inexistencia de una propuesta capaz de justificar tanto la unidad del fenómeno como su asimilación a la realidad peninsular, donde ciertas características específicas justificarían la diversidad y la diferenciación ${ }^{6}$.

Esta respuesta derivaría en la reinterpretación y readaptación de la propuesta toubertiana, a las que cabe incorporar las aportaciones de autores como Wickham ${ }^{7}$, que han llevado a observar en el incastellamento un patrón de representación de los grupos señoriales, que encuentran en el castillo el elemento esencial de expresión. Todo ello debe entenderse, sin embargo, en relación a otros muchos aspectos y factores tales como el contexto político, social y económico específico del propio ámbito espacial y, por derivación, el tipo de relación generado entre la autoridad central y los poderes señoriales.

No es nuestra intención reabrir el antiguo debate sobre el incastellamento y su viabilidad y operatividad peninsular. Por el contrario, hemos considerado más adecuado incidir en el papel desempeñado por los castillos

\footnotetext{
${ }^{5}$ Mínguez 1998, p. 7.

${ }^{6}$ Ibidem, p. 10.

${ }^{7} \mathrm{El}$ autor establece una clara diferenciación entre el incastellamento, como fenómeno vinculado a la construcción del castillo y la nuclearización del poder político, y el accentramento, asociado a la concentración de los asentamientos campesinos. Batet 1995, p. 344.
} 
y el tipo de relación gestado entre los diversos poderes como principios básicos subyacentes a la comprensión de aquél y, en función de ello, de las diferencias y semejanzas que observamos entre Italia y la Península. Para ello proponemos un breve estudio entre los sectores norte y centro italianos -fundamentalmente la región de la Toscana- y la Tierra de Campos -concretamente la ribera del Cea- en la actual provincia de Valladolid. Conscientes de las diferencias que se observan entre ambas, fundamentalmente en virtud de sus dimensiones geográficas, estimamos sin embargo que nos encontramos ante sectores muy representativos de los aspectos que aquí pretendemos abordar, hecho que puede facilitar la estimación de las divergencias existentes entre las dos zonas.

Nuestra finalidad no es otra que observar el rol ejercido por los centros fortificados en relación a los poderes imperantes en la zona, el tipo de evolución que experimentaron en ambos casos, la posibilidad de considerar dichos núcleos como manifestación última de las familias aristocráticas presentes en las zonas de estudio, los factores que favorecieron la manifestación de los poderes señoriales, el tipo de vínculo que se estableció entre ellos o, incluso, el papel desempeñado por la autoridad central en cada caso. A nuestro entender, la consideración y análisis de tales aspectos resulta importante de cara a promover e incentivar el debate científico sobre el incastellamento en el sector noroccidental de la Península Ibérica, así como el estudio del feudalismo y la diversidad de fórmulas y ritmos bajo las cuales su implantación y manifestación se hizo efectiva.

Con esta intención, nos hemos servido de una metodología fundamentada primordialmente en los resultados de los estudios realizados por quienes han dedicado su atención al análisis de ambas regiones, hecho sobre el que creemos conveniente adelantar algunos aspectos. Por un lado, el intenso desfase que a nivel cuantitativo y cualitativo impera entre Italia y la Península Ibérica tanto desde el punto de vista historiográfico como arqueológico en relación a las cuestiones que aquí planteamos; en segunda instancia el grado de repercusión que cuestiones como el incastellamento han alcanzado en nuestro país y la trayectoria de su análisis; y, en último lugar, la proyección del método arqueológico, mucho más temprana en el país vecino y que en nuestro caso comienza ahora a emitir interesantes resultados ${ }^{8}$.

\footnotetext{
${ }^{8}$ Sobre el estado en el que se hallan los resultados de naturaleza arqueológica en relación al papel desempeñado por castros y castillos en el noroeste peninsular remitimos a la reciente obra de Quirós, Tejado 2012.
} 


\section{EL CASO ITALIANO. LOS NÚCLEOS "INCASTELLADOS" EN SU DIMENSIÓN POLÍTICA, SOCIAL Y ECONÓMICA}

Aunque prácticamente toda Italia se ha visto sometida en las últimas décadas a este tipo de investigaciones, ciertas regiones parecen haber captado especialmente la atención de arqueólogos e historiadores. Este sería el caso de la Toscana, donde a los estudios llevados a cabo por Francovich ${ }^{9} \mathrm{y}_{\text {Wickham }}{ }^{10}$, cabría incorporar los de Nuccioti y Leporatti ${ }^{11}$, Augenti ${ }^{12}$, Cortese ${ }^{13}$, Farinelli y Giorgi ${ }^{14}$, Cucini ${ }^{15}$ y Parenti ${ }^{16}$, Valenti ${ }^{17}$ o Quirós ${ }^{18}$, entre otros muchos. Junto a los datos emanados de las intervenciones arqueológicas efectuadas en buena parte de estos asentamientos y cuya relevancia para el periodo en el que nos movemos no podemos omitir, el siglo $\mathrm{X}^{19}$ trajo consigo una considerable ampliación del número de documentos capaces de proporcionarnos información sobre el incastellamento, el desarrollo de los centros fortificados y la representación de los poderes aristocráticos, tanto de naturaleza laica como eclesiástica, que a ellos quedaban vinculados ${ }^{20}$. En efecto, junto a determinadas instituciones monásticas, el obispo actuó desde etapa muy temprana como la figura más representativa del señorío eclesiástico ${ }^{21}$, ejerciendo una notable influencia sobre el fenómeno de reorganización social y económica a través, la mayoría de las ocasiones, de una significativa actividad edilicia.

\footnotetext{
${ }^{9}$ Farinelli, Francovich 1994, pp. 443-465.

${ }^{10}$ Wickham 1990, pp. 79-102.

${ }^{11}$ Nuccioti, Leporatti 2003, pp. 255-265.

${ }^{12}$ Augenti 2000a, pp. 25-66.

${ }^{13}$ Cortese 2000a, pp. 67-110.

${ }^{14}$ Farinelli, Giorgi 2000, pp. 239-284.

${ }^{15}$ Cucini 1989, pp. 49-56.

${ }^{16}$ Parenti 1989, pp. 47-78.

${ }^{17}$ Valenti 2004.

${ }^{18}$ Quirós 1999.

${ }^{19}$ Aún conscientes de la posible construcción de fortificaciones con anterioridad al siglo X, tomamos como punto de referencia esencial esta centuria dada la dificultad de hallar información sobre los castillos de etapa anterior. Quirós Castillo nos informa de la rareza de este tipo de construcciones en el siglo IX para la Toscana, integrando además ésta en un contexto de inestabilidad para el poder central. Como único ejemplo, el autor referencia la actividad fundacional protagonizada por el marqués Adalberto en relación al castillo de Aulla. Véase Quirós 1999, p. 195.

${ }^{20}$ Este hecho no impide documentar un temprano desarrollo de poderes señoriales en cuyas manos quedaron ciertos centros curtenses, orígen de núcleos fortificados. Así sucedería con el castillo de San Magno, en manos del obispo de Volterra. Véase Nardini 1999, pp. 339-351.

${ }^{21}$ Para Augenti, los castillos de origen episcopal se encuentran representados en la Toscana e Italia septentrional a través de un amplio marco temporal, frente a aquéllos de naturaleza pública que no alcanzan representación antes de la mitad del siglo X. Augenti 2000a, p. 46; Augenti 2000b, p. 126.
} 
A partir de los estudios de Quirós Castillo para el territorio de Luca, sabemos de la labor desarrollada por el obispo Pietro II, a quien ha de atribuirse la fundación de los castillos de Santa Maria a Monte, Moriano, Pietrabuona, Anchiano y San Gervasio. Al parecer, y siguiendo en todo momento los razonamientos de este autor, la finalidad que regulaba esta tarea fundacional respondería predominantemente a razones de índole política, facilitando de este modo el nacimiento o afianzamiento de núcleos de población que darían acogida a sectores con los que mantener relaciones de naturaleza clientelar ${ }^{22}$. Algo similar sucedería en la Savonese, con el castillo de Spotorno, erigido para proteger la villa que se ubicaba a los pies de la fortificación ${ }^{23}$ o en la región de Liguria, donde el análisis de las fuentes documentales ha permitido a Benente concluir el papel desempeñado por el poder episcopal durante la primera oleada de construcciones con el fin de generar un marco de encuadramiento político y territorial de carácter episcopal ${ }^{24}$.

Ahora bien, junto al poder eclesiástico, el laico también estuvo ampliamente representado en buena parte de la Italia medieval. Paralela a la actividad protagonizada por las familias condales, que en algunos casos no fue tan significativa, destacó la labor fundacional ejercida por los grupos locales resultando especialmente relevante en el caso de la Toscana el mapa de distribución señorial elaborado por Wickham, quien divide la región en tres grandes sectores en función del grado de representación señorial discernible en cada uno de ellos ${ }^{25}$. El mayor contraste nos lo proporcionarían los sectores norte y sur con un débil desarrollo señorial en la franja central, donde se observa la incapacidad para desarrollar fuerza suficiente como para ejercer el dominio sobre tierras y hombres ${ }^{26}$. Retomando el planteamiento de este autor, el sector septentrional estaría caracterizado por una escasa presencia de los grupos aristocráticos, sobre todo en las proximidades de Pisa y $\mathrm{Luca}^{27}$, donde se acusaría una reorientación más intensa por parte de las aristocracias hacia la participación en la política urbana.

${ }^{22}$ Quirós 1999, p. 195.

${ }^{23}$ Varaldo 2000, p. 147.

${ }^{24}$ Benente 2000, p. 47; Brogiolo, Chavarría 2005, p. 76; Cagnana, Gardini, Vignola 2010, pp. 29-46.

${ }^{25}$ Wickham 1996, pp. 348 y ss. Sobre este particular remitimos al estudio realizado por Carocci sobre el Lazio donde se plantean algunos aspectos comparativos respecto a los estudios planteados por Wickham. Carocci 2001, pp. 67-90.

${ }^{26}$ Cortese avala la propuesta de Wickham al estimar el escaso desarrollo de los poderes señoriales en la zona central. En el caso concreto de Siena se observa un importante vacío señorial en las proximidades de la ciudad, constituyéndose como una excepción los castillos de Berardenghi. Véase Cortese 2000b, p. 218.

${ }^{27}$ Remitimos al estudio realizado por Cortese, ibidem, pp. 205-214. 


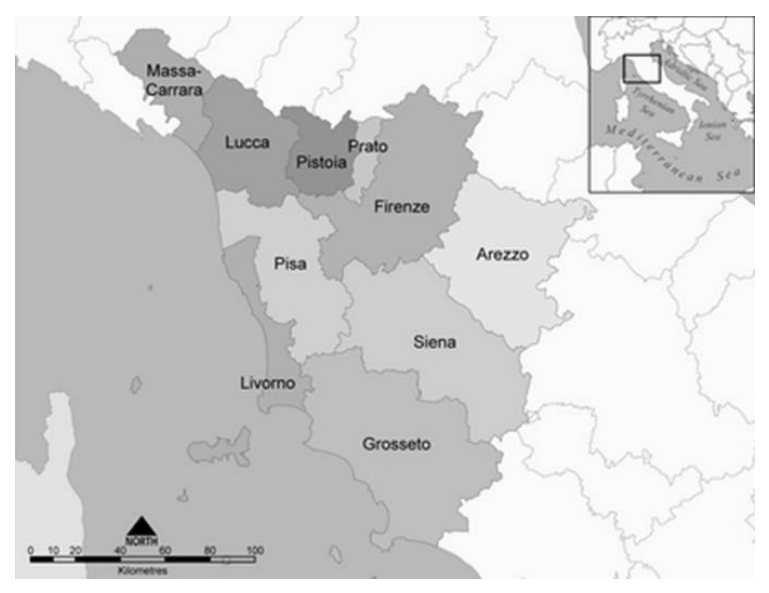

Mapa 1. La región de La Toscana.

La razón esgrimida por el propio Wickham estribaría en el acusado estado de fragmentación de la propiedad ${ }^{28}$, mientras que en el sur estas funciones vendrían representadas por la familia de los Aldobrandeschi y los Gerardeschi. Allí los señoríos ${ }^{29}$ se consolidaron y adquirieron mayor fuerza con un desarrollo de la propiedad diferente al que se adivinaba al norte de la región.

En este sentido, asumir y aceptar la concepción del castillo como centro del señorío rural ${ }^{30}$ y como mecanismo de representación y manifestación del poder señorial en el espacio, nos ayudaría a entender las características y el proceso de configuración que han experimentado tales elementos. Desde este punto de vista, parece lógico que allí donde estos poderes se mostraron más débiles, e incluso ausentes, estas primeras fortificaciones viniesen representadas por estructuras modestas, de pequeñas dimensiones, incapaces de ejercer un impacto grande sobre los hábitats de las áreas circundantes ${ }^{31}$, al contrario de lo que sucedería con aquellos centros dispuestos en manos de las

\footnotetext{
${ }^{28}$ Wickham 1996, pp. 363-364. Esta visión parece ser compartida por Violante, quien estima que tanto en Italia septentrional como central la menor extensión y más acusada fragmentación de las propiedades fundiarias y la interposición de numerosas propiedades medianas y pequeñas favorecen la dispersión de los asentamientos. Véase Violante 1996, p. 54.

${ }^{29}$ Aun conscientes de la complejidad que puede entrañar un término de semejantes características, se ha procedido a la traducción literal de signoria por señorío. Para profundizar sobre estas cuestiones véase Carocci 2007, pp. 137-157.

${ }^{30}$ Wickham 1998, p. 34.

${ }^{31}$ Wickham 2010, p. 278.
} 
grandes familias aristocráticas. Quizás el ejemplo más llamativo de castillo señorial toscano nos lo proporcione la fortificación de Rocca San Silvestro, un villagio fortificado ${ }^{32}$ destacable sobre todo por el vínculo que se genera entre éste y la zona minera de la Maremma pisana, en la que se localiza ${ }^{33}$. Su fundación recayó en manos de la familia señorial de los Gerardeschi, una de las principales parentelas de la región. Una de las razones fundamentales que se ha argumentado en relación a su origen es la del ejercicio del control de los recursos metalúrgicos que se localizan en las proximidades por parte de los señores. El hecho revela claramente el papel desempeñado por la fortificación en la reorganización social y económica del territorio dependiente del mismo, pareciendo clara por tanto la presencia de un fuerte control señorial sobre los procesos de producción. Sus propias características formales y materiales han sido interpretadas en relación directa con el incastellamento y con la presencia de poderes señoriales dotados de capacidad suficiente para garantizarlo ${ }^{34}$ y ejercer el control sobre los distintos procesos de transformación metalúrgica ${ }^{35}$.

Pero posiblemente la característica más destacable del incastellamento, y sobre la que tradicionalmente más se ha llamado la atención, sea la disposición y encuadramiento del poblamiento en el interior del recinto amurallado, lo que de por sí trae consigo ciertas consecuencias entre las que hemos de destacar un cambio en el modelo de asentamiento ${ }^{36}$. Los datos derivados de los estudios e intervenciones arqueológicas efectuadas en los últimos años nos permiten observar la existencia de un hábitat diverso en el que se conjugan las formas dispersas y concentradas, con una mayor prevalencia de estas últimas sobre todo a partir del siglo VII, aunque siguiendo ritmos y formas muy diversos en cada región ${ }^{37}$.

${ }^{32}$ Francovich, Wickham 1994, p. 7. Cucini estima la fundación y origen del castillo a finales del siglo X y principios del XI como villa minera y metalúrgica. Véase Cucini 1989, p. 55.

${ }^{33}$ Se documentan casos similares en relación al ejercicio del control sobre los recursos mineros por parte del monasterio de San Pietro, en Monteverdi o San Salvatore. Para un estudio más pormenorizado sobre estas cuestiones remitimos a Farinelli, Francovich 1994, pp. 451-452.

${ }^{34}$ En este sentido resultaría interesante el estudio realizado por Francovich, Bianchi 2002, pp. 101-111.

${ }^{35}$ Francovich, Wickham 1994, p. 19. Para profundizar en este estudio, véase Farinelli, Francovich 1994, pp. 443-465. Al margen de Italia, contamos con interesantes ejemplos que revelan una tendencia hacia la generalización de estos hechos. Así parecen revelarlo las intervenciones realizadas en Francia. El lugar de Colletière ha deparado lo que se ha dado en considerar como un hábitat aristocrático, dotado de estructuras orientadas al ejercicio de actividades metalúrgicas y textiles. Morsel 2008, pp. 110-111.

${ }^{36}$ Efectivamente, la concentración de las comunidades campesinas que queda ligada a este fenómeno parece ser la consecuencia de los cambios operados en algunos sectores geográficos ya en el periodo de la tardoantigüedad. Así parecen demostrarlo las intervenciones realizadas en Poggibonsi o Montarrenti. Para analizar con más detalle su evolución. Brogiolo, Chavarría 2005, pp. 116-117 y Augenti 2000a, p. 35.

${ }^{37}$ Wickham 2010, p. 277. 
A partir del siglo VIII comienza a hacerse evidente el esfuerzo orientado a la concentración de los medios de producción y de las familias campesinas dependientes, sin otra intención que garantizar y favorecer el control del trabajo y el logro de excedentes por parte de las élites. Los espacios productivos y residenciales comienzan a dividirse con mayor claridad y se dotan de elementos de diferenciación y fortificación, como se observaría en Staggia para los siglos IX y $\mathrm{X}^{38}$. Todos estos hechos quedan asociados al deseo de reestructuración territorial por parte de los señores rurales, haciendo de este modo posible el surgimiento de un sistema jerarquizado presidido por el castellum. Hemos tenido ocasión de comprobar, además, que las transformaciones experimentadas por la gran propiedad condicionaron la configuración y estructuración de los señoríos. La fragmentación a la que se vio sometida la gran propiedad $^{39}$, con especial intensidad en algunos sectores de la región la Toscana, contribuyó a dificultar la concentración de propiedades en manos de los poderes señoriales y por tanto también el ejercicio del control territorial ${ }^{40}$.

$\mathrm{Si}$ éste es el desarrollo que, en términos generales, contemplamos para los siglos VIII-X, es a partir de este último y sobre todo en el XI y XII cuando podemos constatar la formación y consolidación de la señorialización marcada por la dotación de derechos de índole diversa, como sucedería en el caso de los canónicos de Santa María de Novara que tenían en propiedad el castillo de Mosezzo y los derechos de jurisdicción señorial y tributación fiscal sobre quienes allí trabajasen ${ }^{41}$. Las muestras son evidentemente numerosas, si bien lo que nos interesa en este caso es reafirmar la existencia del castillo como elemento vinculado a la presencia señorial y a la conformación paulatina de unos señoríos sobre los que resultaría posible la aplicación de diversos derechos.

\subsection{Juego de poderes: ¿implicación de la autoridad central?}

Llegados a este punto podemos cuestionarnos ¿qué subyace realmente bajo este fortalecimiento señorial?, ¿bajo la capacidad de representación del poder aristocrático a través de las fortificaciones?, ¿bajo el control y dominio ejercido desde estos centros sobre los recursos humanos y económicos? Hemos hecho referencia, hasta ahora, al devenir de los señores y su relación

\footnotetext{
${ }^{38}$ Valenti 2007, p. 225.

${ }^{39}$ Las cuestiones vinculadas al régimen económico y sus modificaciones fueron estudiadas en detalle por Toubert 1973, pp. 305-545.

${ }^{40}$ Wickham 1996, p. 363-364. Violante 1996, pp. 53-54.

${ }^{41}$ Andenna 1996, p. 152.
} 
con los centros fortificados. Sabemos que la presencia de algunos de ellos se hizo efectiva de forma relativamente temprana y que el cuadro de distribución de éstos no fue uniforme. No obstante, el nacimiento y divulgación de estas aristocracias locales y, por tanto, de los señoríos que a ellas quedan ligadas, ha de ponerse en relación directa con el propio proceso de evolución y desarrollo de otros poderes ${ }^{42}$.

Fumagalli ${ }^{43}$ refiere en su estudio sobre la sociedad padana la situación de crisis a la que tuvo que enfrentarse la monarquía -y con ella la nobleza tradicional- desde finales del siglo IX y durante la décima centuria. Las consecuencias de esta situación serían, por un lado, desbaratar la estructura organizativa precedente $\mathrm{y}$, por otro, el debilitamiento del poder regio que vendría acompañado de un ferviente impulso de otros representantes de la aristocracia, en gran medida eclesiástica. El estado en el que se encontraba la monarquía en este momento requería necesariamente la adopción de algunos parámetros de actuación que reportasen soluciones. Entre ellas destacó la concesión regia como medida necesaria para garantizar la propia estabilidad, a través del respaldo y ayuda proporcionada por los grupos de poder señorial, facilitando la consolidación de unos lazos bidireccionales de correspondencia mutua, similares a los que documentamos en otros países inmersos en la órbita feudal. Entre los casos más representativos destacaría la concesión realizada por el emperador Guido, en el año 861, a favor del obispo de Módena. Dicha concesión conllevaba en este caso el derecho de fortificación de la ciudad y sus cercanías ${ }^{44}$. En el año 923, la corte ducal de Belluno es consignada al obispo de aquella ciudad ${ }^{45}$.

Al margen del fuerte crecimiento experimentado por las figuras episcopales, las relaciones entabladas por el poder central no se limitaron exclusivamente a estas figuras. En el año 760 el rey Desiderio y Adelchi y la reina Ansa donan sus bienes al monasterio de San Salvatore de Brescia. La concesión incluía casas masaricas numero decem positis super fluvio Ollio, locus qui Pisserisse nuncupatur ${ }^{46}$. Nos interesa destacar la interpretación que para el autor merece esta concesión, pudiendo darse el hecho de que estas casas

\footnotetext{
${ }^{42}$ Brogiolo y Chavarría insisten en el relevante papel desempeñado por la autoridad estatal y por las aristocracias en la comprensión del fenómeno de los castillos de primera generación en Italia. Brogiolo, Chavarría 2005, pp. 75-76.

${ }^{43}$ Fumagalli 1974, pp. 68-85.

${ }^{44}$ Sabemos que ésta era una prerrogativa exclusiva del poder central y que se hace evidente en el edicto de Pîtres del año 864. Morsel 2008, p. 125.

${ }^{45}$ Fumagalli 1974, p. 75. De forma similar, entre los años 902 y 913 el rey concede a un tal Lupo de Gorgo el permiso de fortificación. Fumagalli 1974, p. 98.

${ }^{46}$ Fumagalli 1984, p. 202.
} 
formasen parte o integrasen una corte $^{47}$, considerada como el posible centro administrativo urbano regio en Brescia ${ }^{48}$. El mismo Adelchi otorga, el 11 de noviembre del año 772, un documento a favor del citado monasterio por el que se especifica la concesión de un conjunto de posesiones et curtes ibidem concessas atque largitas, que pertenuerant ex iura curtis nostrae regie que et ex iura curtis docalis ${ }^{49}$. Finalmente, en el año 853, Ludovico II confirma la concesión realizada por Pipino por la cual el monasterio de San Zeno de Verona obtenía in regalibus tam silvis quam et in ceteris pascuis... greges ovium... nec non et pecorum iumentorumque vel ceterorum animalium ad ipsum monasterium pertinentia ${ }^{50}$.

Se trata realmente de ejemplos muy parcos, aunque destacables por fecharse de forma muy temprana y por permitirnos establecer cierto grado de conexión entre ambos poderes, central y aristocrático. Concesiones semejantes vienen a reflejar, desde nuestro punto de vista, el desarrollo y engrandecimiento que experimentan algunos de estos poderes y que deben sumarse al que otros tantos señores venían arrastrando desde tiempo atrás. Siguiendo el planteamiento de Fumagalli, estas relaciones no respondían tanto a una elección política como a un estado de necesidad de reafirmación, contexto éste en el que se insertaría la actuación emprendida por el obispo Guido, encargado de liderar la rebelión contra Ugo de Provenza, a favor de Berengario II, recibiendo a continuación y como compensación por la ayuda prestada el control de Nonantola ${ }^{51}$.

Esta capacidad de control y dominio creciente que alcanzan los poderes locales desde el siglo IX se refleja a través del aumento del número de fundaciones fortificadas. Incremento que ha sido tradicionalmente interpretado como un engrandecimiento de los grupos aristocráticos en detrimento del poder central, cada vez más debilitado y sumido en crisis. Morsel, por el contrario, expone la necesidad de comprender el concepto de "castellanización", no tanto como resultado de la fragmentación y fraccionamiento del poder, sino como consecuencia del "anclaje espacial de ese poder" y entendiendo este proceso en función de las relaciones y sistemas de representación sociales que se gestan y desarrollan entre los siglos X y XII ${ }^{52}$. Pero es cierto que, ni estos vínculos se desarrollaron siempre de forma pacífica -dibujando un panorama

${ }^{47}$ En el texto se especifica: "Necnon et cedimus ibi recona, quantum ad curtem nostram pertinet". Ibidem, p. 202.

${ }^{48}$ Ibidem, p. 203.

${ }^{49}$ Ibidem, p. 204.

${ }^{50}$ Fumagalli 1978, p. 58.

${ }^{51}$ Fumagalli 1974, p. 79.

${ }^{52}$ Morsel 2008, p. 129. 
similar al que se perfila para otras monarquías occidentales- ni se limitaron exclusivamente al poder central. Ciertas fuentes escritas nos permiten reconocer la existencia de disputas habidas entre diferentes facciones por el control de algunos castillos, como sucedería con la fortificación de Montelaterone por la que pugnarían la abadía de San Salvatore, el linaje Aldobrandeschi o la comuna de Siena ${ }^{53}$.

De forma paralela, el mapa elaborado por Wickham nos permitía extraer algunos resultados sobre las pautas de distribución señorial. En el caso de la Toscana, los núcleos urbanos más potentes actuaron como ejes de atracción de ciertos grupos aristocráticos involucrados en las actividades gestoras propias de la ciudad. El hecho condicionó la conformación de señoríos que alcanzaron consecuentemente mayor peso en las áreas menos pobladas y urbanizadas donde fueron capaces de ejercer un control y dominio territorial más intenso. El caso excepcional lo constituiría la ciudad de Florencia, lugar en el que los señoríos se hacían visibles a través de una red de castillos en cada ángulo del condado ${ }^{54}$.

Esta participación de la urbe italiana en la señorialización y su difusión quedaría patente de forma similar a través de la concesión protagonizada por Génova, en el año 1132, a favor del marqués Opizzo Malaspina y que conllevaba, en este caso, el control sobre cinco mansiones y terreno para edificar en el área del castillo. Los genoveses, que en esta fase inicial contra los poderes locales parecen apoyarse en los marqueses, donan una parte de la tierra insuper et in iusu monte Rivaroli, de modo que los hombres de Opizzo construyan casas ad habitandum ${ }^{55}$.

Estos son, de forma un tanto genérica, los principios que regulan el complejo entramado señorial que identificamos en la región de la Toscana, objeto de mayor interés por parte de arqueólogos e historiadores. Como podemos concluir, se trata de un fenómeno de elevada heterogeneidad tanto desde el punto de vista espacial como temporal, fundamentado en la articulación y confluencia de poderes muy diversos y del tipo de relación -no siempre pacífica- gestado entre todos ellos. Es evidente que un tema de semejantes características requeriría de un estudio mucho más profundo, que aquí no podemos abordar. Nuestro objetivo, reiteramos, no es otro que plantear una serie de aspectos básicos que nos permitan observar algunas diferencias respecto a la situación que encontramos en la ribera del Cea.

\footnotetext{
${ }^{53}$ Nucciotti, Leporatti 2003, p. 256.

${ }^{54}$ Wickham 1996, pp. 348-359.

${ }^{55}$ Frondoni, Benente, Garibaldi 2000, p. 191.
} 


\section{CENTROS DE PODER Y PODERES EN TIERRA DE CAMPOS. LA RIBERA DEL CEA}

Hemos de iniciar este apartado reconociendo que en la Península Ibérica el tema del incastellamento no cuenta con una tradición historiográfica -y mucho menos arqueológica- tan amplia como en el caso de Italia. Desde este último punto de vista, cabe destacar la tardía implicación de la arqueología en el estudio de la etapa medieval, con una mayor incidencia en otros contextos históricos. Será en la década de los años 80 del siglo XX cuando, paralelamente a la renovación del debate historiográfico, el método arqueológico comience a operar en nuevos ámbitos de actuación entre los que resultará posible incluir el medieval. De tal manera, la ampliación temática y la apertura de nuevas líneas de investigación -entre las que destacarían el estudio de los patrones territoriales y de poblamiento altomedievales- se verán complementadas y favorecidas por las contribuciones del registro material y los resultados derivados de estudios y análisis espaciales fundamentados en la utilización de recursos metodológicos de naturaleza geográfica. No obstante, todo ello no impide advertir la existencia de interesantes aportaciones en relación a las cuestiones que aquí se vienen planteando y que, en ningún caso, resultaron ajenas al análisis que sobre el feudalismo se estaba llevando a cabo en la Península ${ }^{56}$. Si bien es cierto que la mayoría de estos estudios se encaminan a reafirmar o, por el contrario, desmentir la operatividad regional de un proceso de semejantes peculiaridades tal y como se pone de manifiesto en los ejemplos que citamos a continuación.

A finales de los años 90 y a raíz de la celebración de los encuentros de Girona y Roma, que tomaron como eje central de debate el tema del incastellamento, Mínguez Fernández negaba con cierta rotundidad la viabilidad de una propuesta semejante en el norte peninsular dadas las características específicas de este sector ${ }^{57}$, de manera que las diferencias entre ambos países eran demasiado notables como para permitir esta posibilidad. Años más tarde los estudios realizados en el castillo de Treviño por Quirós Castillo -y a los que se suman las investigaciones realizadas en el País Vasco o Navarra- contribuían a perfilar el panorama que se dibujaba en el norte peninsular. Los resultados derivados de tales análisis han llevado al autor a afirmar que el castillo nacía para dar así respuesta a una forma de experimentación política por parte de las élites emergentes compatibles con los procesos de configuración de los poderes centrales ${ }^{58}$.

\footnotetext{
${ }^{56}$ Sin ánimo de exhaustividad cabe citar a autores como Mínguez 1998, pp. 7-12; Martín 2001, pp. 83-110; Quirós 2011, pp. 113-136; Batet 1996.

${ }^{57}$ Mínguez 1998, pp. 10-12.

${ }^{58}$ Quirós 2011, p. 134.
} 
A estas conclusiones, y con el fin de profundizar en el conocimiento sobre el papel desempeñado por las fortificaciones en la gestación y desarrollo del feudalismo, Martín Viso ${ }^{59}$ incorporaba su concepción de éstas como núcleos de poder político lejanos, sin embargo, al desempeño de funciones relativas a la acumulación de derechos señoriales. Propuesta que derivaba en una relativización del centro fortificado que de este modo perdía peso a favor de otros entes, entre los que destacarían las villas, como puntos de partida de la propiedad feudal.

El tema se ha retomado recientemente a raíz de las intervenciones arqueológicas emprendidas en algunos de los sectores de la franja noroeste, destacando los planteamientos recogidos nuevamente por Quirós Castillo. Según estima el autor, aunque es cierto que en ningún momento se defiende con rotundidad la posibilidad de hablar de incastellamento en Tierra de Campos sí se retoma, a partir de los resultados extraídos de la obra de Martínez Sopena, la emergencia y nacimiento de ciertas aldeas a la luz del castillo ${ }^{60}$. Evidentemente, se trata de un análisis que requeriría una profundización mucho más intensa de la que aquí realizamos, si bien reiteramos que en este estudio se plantean algunas pautas y condicionantes que consideramos esenciales a la hora de hablar del incastellamento como paradigma que supera la mera concentración del poblamiento dentro del recinto amurallado y se inserta en las propias relaciones de poder. De todas estas aproximaciones se desprende un alto grado de heterogeneidad que se acrecienta si las valoramos con relación a las conclusiones extraídas para lugares como Cataluña. Allí, las investigaciones emprendidas por Batet i Company en un intento de determinar el grado y tipo de relación entablada entre el núcleo fortificado y la captación de la renta campesina, han llevado a la autora a valorar el castell termenat como célula de encuadramiento de la población hecho que, por otro lado, vendría a facilitar y favorecer la participación de los magnates en el proceso de producción ${ }^{61}$.

A la luz de tales hechos podemos preguntarnos ¿qué características pudieron definir el feudalismo en el sector noroccidental?, ¿qué tipo de vínculo se gestó entre los diversos poderes que confluyen en la zona?, ¿qué papel podemos atribuirle aquí a los centros fortificados? Se trata de cuestiones de respuesta compleja para las que intentaremos emitir algunos datos tomando como punto de referencia geográfico el espacio que comprende la ribera del río Cea, en la comarca de Tierra de Campos, actual provincia de Valladolid.

\footnotetext{
${ }^{59}$ Martín 2001, p. 104.

${ }^{60}$ Quirós 2012, p. 24.

${ }^{61}$ Batet 1996, p. 93.
} 
Un espacio de llanura especialmente apto para el cultivo, irrigado por las aguas del río que le da nombre y roto de forma casi exclusiva por la presencia de pequeños cerros de escasa altitud.

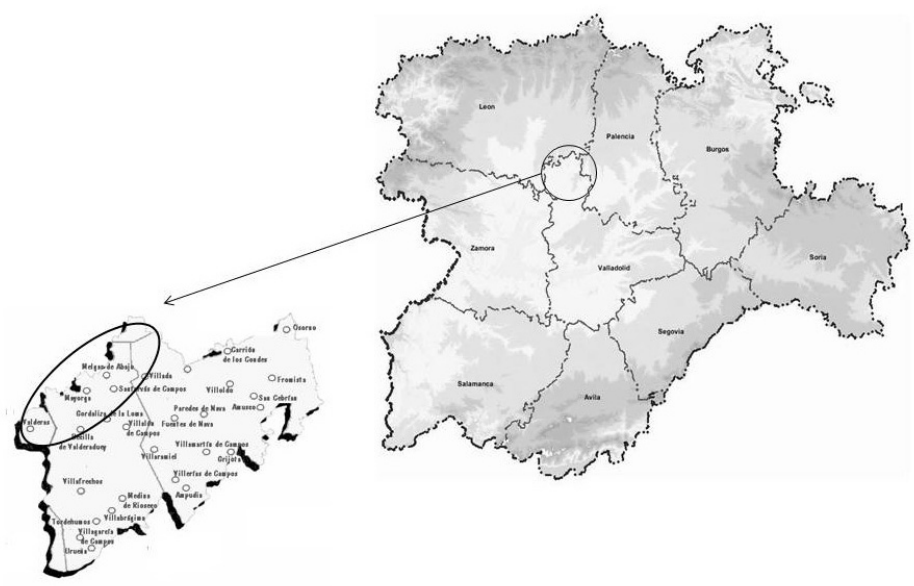

Mapa 2. La ribera del Cea.

\subsection{Los castros y la jerarquización territorial}

Antes de abordar con mayor detalle esta cuestión, cabe destacar algo que a estas alturas parece haber quedado suficientemente claro, y que no es otra cosa que la conexión existente entre los poderes señoriales y ciertos núcleos de representación. En nuestro caso se trata, en la mayoría de las ocasiones, de asentamientos en altura, castros que cuentan frecuentemente con un origen prerromano y que se hallan distribuidos por el valle del Cea, muy próximos al río, actuando desde antiguo como puntos clave en la organización del territorio circundante y los recursos que en él se localizan.

En el caso que nos ocupa este vínculo resulta especialmente visible, contando con referencias documentales para lugares como Castro Mazaref (Valderas), Castro Abaiub (Castrobol), Castro Froila (Mayorga), Castro Abduci (Melgar de Abajo), Castro Forakasas (Melgar de Arriba), capaces de ejemplificar el panorama que se descubre en las riberas del Cea, Valderaduey y Esla ${ }^{62}$. Como puede apreciarse en la mayoría de las ocasiones, y salvo algu-

\footnotetext{
${ }^{62}$ Podríamos ampliar este listado con topónimos como Castro Gundisalvo, (Castrogonzalo) Castropepe, Castro Domnino (Castro Ponce) Castro de Azebal (Castrello)... Véase Martínez 1985, p. 99 y pp. $118-125$.
} 
na excepción, se trata de topónimos surgidos a partir de la palabra "castro" a la que se añade un antropónimo frecuentemente de raíz árabo-bereber ${ }^{63}$. Según diversos autores ${ }^{64}$ estos antropónimos podrían corresponder a grandes propietarios de la zona, figuras vinculadas incluso al monarca y encargadas por delegación del mismo de reorganizar a los grupos de población existentes en la zona. La propia documentación nos informa de la presencia de grupos -posiblemente familiares- que en un periodo precedente se habían ido asentando en el lugar, conformando un sistema de articulación y ordenación basado en la collatio, término que en este caso podría ser sinónimo de concilio o asamblea $^{65}$ y que da fe de la existencia de un modelo de organización social previo al avance repoblador y que hacía posible la vida de la comunidad. De uno de estos concilios tenemos constancia a través de un documento fechado en el año 932. Se trata de la venta que Filauria y otras ocho personas, representando a la collatio de Melgar, realizan a favor del monasterio de San Juan, al que conceden un prado en Fontoria, próximo a Melgar ${ }^{66}$. Llegados a este punto, cabe prestar atención a la denominación de Melgar en tanto que este topónimo de supuesto origen prerromano ${ }^{67}$ se complementa un poco más tarde, en el año 945, con el antropónimo de Forakasas ${ }^{68}$, personaje vinculado a la actividad de reorganización de la población y del territorio. Desde este punto de vista, Forakasas iben Tajon continuaría con la labor de organización iniciada por su padre años antes, al mismo tiempo que ampliaría su propio patrimonio como parecen evidenciar las distintas donaciones que tanto él como su viuda realizarían ${ }^{69}$.

Aunque significativo, no es el único caso que podemos identificar para el valle del Cea, pues algo similar podría haber sucedido con Abduci, fundador de la villa de Abduz, documentada en el año 98570; Mazaref, considerado padre del repoblador Godesteo y presunto fundador del castro que lleva su

\footnotetext{
${ }^{63}$ Para profundizar en estas cuestiones remitimos a la obra de Carrera 1988.

${ }^{64}$ De especial interés resultan las aportaciones de Mínguez 2009, pp. 199-214; Martínez 1985, pp. 96-100.

${ }^{65}$ Martínez 1985, p. 113; Rodríguez 2007, p. 71.

${ }^{66}$ CDMS (ss. IX-X), doc. 44.

${ }^{67}$ Mínguez 2009, p. 209.

${ }^{68}$ Sabemos que Forakasas era hijo de un tal Tajon, fiel servidor de rey Ordoño II como se concluye a partir de la propia documentación. Así, en el año 920, este monarca entrega a Tajon, "fideli nostro" la villa de San Miguel de Boadilla. Véase Rodríguez 1982, pp. 47-48.

${ }^{69}$ En el año 955, Foracasas eben Taione "infirmitate detentus" dona a Sahagún la mitad del lugar de Boadilla de Rioseco, la pausata de San Miguel y el lugar de Villanueva. (CDMS-ss. IX$X$, doc. 144). Al año siguiente, 956, Doña Infante, viuda de "vir meus Foracasas filius Taioni", dona a Sahagún la heredad de su marido, añadiendo las aldeas de Cáscaras y Cascarillas, más una viña, heredades de su padre Azuaque, en la villa de este nombre, (CDMS-ss. IX-X, doc. 150. )

${ }^{70}$ Carrera 1988, p. 132.
} 
nombre ${ }^{71}$; o con Fruela, encargado de articular el territorio en torno al centro de Castrofroila, documentado ya por vez primera en el año 891, momento en que Alfonso III dona al monasterio de San Adriano de Tuñón una villa e iglesia in valle de Castro Froila ${ }^{72}$. Lo que hallamos, en definitiva, no es otra cosa que la adopción y puesta en marcha de una serie de medidas incentivadas por la monarquía y encaminadas a favorecer la organización del territorio y de los grupos de población y facilitar, por tanto, la progresiva incorporación de estos espacios al programa político que la propia autoridad central iría desplegan$\mathrm{do}^{73}$. Para ello, como hemos visto, la monarquía se serviría de ricos propietarios que contaban con amplios bienes y propiedades difundidas por la zona en cuestión y sus proximidades y que hicieron del castro, al que la mayor parte de ellos daría nombre, el centro desde el que se llevarían a cabo estas tareas de ordenación estimulando la jerarquización y la paulatina concentración de las villas que se irán distribuyendo en torno a él. Es muy probable que estos personajes que las fuentes nos presentan como miembros destacables dentro de la comunidad y que despuntan por su mayor nivel económico, desempeñasen una importante función como intermediarios entre ésta y los representantes de las más altas cotas de poder.

Llegados a este punto y siguiendo los postulados defendidos por Martín Viso y Escalona Monge ${ }^{74}$ para otros ámbitos geográficos, cabría la probabilidad de presuponer la existencia de unos poderes de carácter local previos a la repoblación y, consecuentemente, a la integración de estos espacios al programa regio. Esta posibilidad y la preexitencia de una población bien organizada y capaz de actuar como engranaje entre el mundo antiguo y medieval en pro de una realidad sin solución de continuidad, nos ayudaría a salvar importantes lagunas historiográficas y a comprender con mayor facilidad la progresiva configuración de las diferentes unidades territoriales de las que tenemos constancia en el siglo $\mathrm{X}$. Es probable que en un futuro la actividad arqueológica, al amparo del impulso que viene observando, sea capaz de arrojar algo de luz en relación a los razonamientos defendidos por estos

\footnotetext{
${ }^{71}$ Ibidem, p. 157.

72 "In nomine Patris et filii et Spiritu Sancti, dompnis gloriosis... Nos famuli vestri Adefonsus rex et Xemena regina in Domino sempiterna salute... villa que dicunt Macanena cum suas apprestancias secundum quod servus noster dato nostro obtinuit, et in valle Castro Froila villa Bovatella cum ecclesia Sanctis Feliciis iusta fluvium" (CDCO, doc. 13).

${ }^{73}$ Hay que destacar que la progresiva incorporación territorial al programa regio y la fórmula bajo la cual se hace efectiva la consolidación del poder central en cada uno de estos territorios, se encuentra condicionada por factores muy diversos que se vinculan a la propia actividad repobladora. Todos estos planteamientos, que por su importancia deben abordarse a través de un estudio independiente, sobrepasan con creces los límites de este trabajo. Como ejemplos véase Martín 2012 y Carvajal, Martín 2013,pp. 39-52.

${ }^{74}$ Martín 2000; Escalona 2002; 2001, p. 26.
} 
autores y profundizar en los aspectos que en este trabajo se abordan. Si bien hemos de reconocer que, hoy por hoy y a la luz de los datos disponibles, este planteamiento se convierte en mera conjetura viéndonos obligados a trabajar con los datos disponibles.

En el año 967 Melgar de Foracasas aparece recogido en la documentación como suburbio ${ }^{75}$ y en el año 990 se cita el territorio de Mazarefe $^{76}$. Estas unidades territoriales, dotadas de carácter político y articuladas desde un centro rector que desempeñaba una función jerarquizadora, acogían en su interior a los diferentes núcleos de habitación y producción campesina, como el ya citado Castro Foracasas, futuro Melgar de Suso o de Arriba. Según afirma Rodríguez Fernández, fundamentándose a su vez en el estudio realizado por Sánchez Badiola, el territorio de Melgar pudo estar integrado por una amplia serie de villas que definían la comarca y que venían a extenderse por diversos municipios actuales. Talavera de Fratres, Villacorta, Villa Pausata, Villa Abduz, Valparaíso, Villa Alvín, Golpejeras, Monasterio de Vega, San Felices de Bovatella ${ }^{77}$ y un largo etcétera, serían algunos de estos ejemplos. Independientemente de que todas ellas y otras tantas formasen parte de este distrito, las fuentes escritas nos permiten confirmar algunas de estas apreciaciones. Así sucedería con la iglesia de San Mamés, de la que se especifica estar situada en este territorio de Melgar ${ }^{78}$, super amnem vocitato Ceia $^{79}$, la propia villa de Foracasas iuxta Melgare in termino iuxtra fratres $^{80}$; Villa de Claudio de termini de Forakasas ${ }^{81}$, o Eglesia Alva in territorio Kastro Mazaref, segus flumen Zegia ${ }^{82}$.

A partir del siglo XI comienzan a observarse ciertas transformaciones, de manera que expresiones tales como per castello vellio de Castrovaiu ${ }^{83}$ evidencian el debilitamiento y decadencia que a estas alturas experimentan

\footnotetext{
75 "qui este secus flumine Ceia in suburbio Melgare castro". CDMS-(ss. IX-X), doc. 246. Como territorio es citado en el año 1073: "orta fuit intemptio inter fratres de Domnis Sanctiis et fratribus Sancti Petri de Eselonza pro ecclesia parroquitana vocabulo Sancti Mametis, territorio Melgare, super amnem vocitato Ceia”. Alfonso VI, doc. 21.

76 "Sub trino, eximio deitatis... in cuius onore dedigata est eglesia et continentium fratrum iugum Dei ividem portentibus in logum predictum que vocitant Eglesia Alva, in territorio Kastro Mazaref, segus flumen Zegia" (CDCL-III, doc. 538).

${ }^{77}$ Rodríguez 2007, p. 73.

${ }^{78}$ Las intervenciones arqueológicas realizadas en el entorno de Melgar de Arriba han deparado restos fechados en los siglos X-XII. Arranz, Gómez, Parrado 1991-1992,pp. 127-138. En Melgar de Abajo, la fotografía aérea ha permitido reconocer trazas de una fortificación medieval. San Miguel 1995, pp. 307-317.

${ }^{79}$ Alfonso VI, doc. 21.

${ }^{80}$ CDMS-(ss. IX-X), doc. 100.

${ }^{81}$ Ibidem, doc. 298.

${ }^{82}$ CDCL-III, doc. 538.

${ }^{83}$ CDME, doc. 72.
} 
algunos de estos centros que paulatinamente serán sustituidos o absorbidos por otros núcleos cercanos ${ }^{84}$. Pero bajo estas transformaciones subyace otra serie de cambios estrechamente vinculados, por un lado, al fortalecimiento y enriquecimiento que a lo largo de la etapa precedente han ido alcanzando ciertos poderes señoriales, tanto laicos como eclesiásticos y, por otro, las propias relaciones entre los distintos grupos de poder. La principal motivación de aquellas élites señoriales que se habían ido forjando a lo largo del siglo X fue el acrecentamiento y mejora de su posicionamiento y la patrimonialización de sus funciones y prerrogativas ${ }^{85}$. Al mismo tiempo la monarquía se veía en la necesidad de contar con el apoyo y respaldo señorial en un intento de garantizar su propio estatus y la progresiva incorporación territorial al reino.

En cualquier caso, la acumulación de propiedades y bienes en manos de estas familias aristocráticas y, lo que es más importante, la concentración de un poder de carácter jurisdiccional que pasan a ejercer de manera cada vez más autónoma, acabará por favorecer la emergencia de un nuevo tipo de organización política ${ }^{86}$, asistiéndose por tanto, a una paulatina señorialización del territorio y una privatización del poder jurisdiccional ${ }^{87}$. Uno de los resultados de la orientación que van tomando todos estos acontecimientos será en última instancia la reacción regia y su implicación directa, a partir sobre todo de mediados del siglo XI, en los procesos de reorganización administrativa y territorial. Ello no supuso un cambio violento en las formas y procedimientos previos, sino lentas modificaciones que comienzan a hacerse evidentes -aunque de forma aún muy tímida- ya bajo el reinado de Alfonso $\mathrm{V}^{88}$, aunque se potenciarán más adelante, sobre todo bajo los gobiernos de Fernando $\mathrm{I}^{89}$, Alfonso $\mathrm{VI}^{90} \mathrm{y}$, fundamentalmen-

\footnotetext{
${ }^{84}$ Castro Abaiub parece quedar adscrito jurisdiccionalmente al señorío realengo de Mayorga en el año 1201. Véase Rodríguez 1968, p. 320. Una situación parecida se dará en Castro Mazarefe, reemplazado por Valderas, Castro Foracasas por Melgar de Suso o Castro Froila por Mayorga que acabará por convertirse en importante sede de poder. Mínguez 2007b, p. 56.

${ }^{85}$ Torres 1999, pp. 418-419.

${ }^{86}$ Mínguez 2007a, p. 22.

${ }^{87}$ Luis 2003, p. 99.

${ }^{88}$ En este contexto puede resultar interesante la referencia en el año 1010 a un maiorino de Luna, cargo ejercido por un tal Fromarico. Para un análisis más detallado remitimos al estudio de Mínguez 2007b, p. 64.

${ }^{89}$ Martínez 2007, p. 145.

${ }^{90}$ Autores como Estepa Díez estiman que el reinado de Alfonso VI se convierte en uno de los gobiernos más interesante en cuanto al origen de los merinos. Estepa 2006, p. 89. Sobre el reinado de este monarca destacan las aportaciones de Santamaría 2009, pp. 185-194. A modo de ejemplo el estudio de la documentación regia, elaborada durante los reinados de Fernando I y Alfonso VI, pone de manifiesto estas diferencias fundamentadas en un notable incremento -en este último caso- del número de referencias a estos cargos. Como fuentes de análisis: Blanco 1986, pp. 7-212.
} 
te, Alfonso VII ${ }^{91}$. Bajo el gobierno de estos monarcas tiene lugar la adopción de ciertas fórmulas encaminadas a restringir los privilegios con los que se habían venido haciendo los distintos linajes aristocráticos y materializadas en cargos como el de tenente o merino.

Pero estos cambios se traducen asimismo en la emergencia de un nuevo tipo de relaciones de poder ${ }^{92}$, hasta tal punto que podemos afirmar que la naturaleza de este "intervencionismo" regio será el que marque una de las grandes diferencias con respecto a la situación de Italia, donde la presencia del monarca parece ser menos intensa ante una aristocracia probablemente más fuerte que la peninsular. Este contraste resulta aún más evidente si se tiene en cuenta la información proporcionada por la documentación del siglo XI, a través de la que se hace evidente la presencia directa de la monarquía en alguno de los enclaves que se alzan en la ribera del Cea. Uno de los mejores ejemplos al respecto nos lo proporciona un texto fechado en el año 1057 por el que sabemos del enfrentamiento entre el monasterio de Sahagún y Gutier Vélaz por la villa de Adda, hecho por el que los litigantes comparecen ante Fernando I en Castro Froila ${ }^{93}$. No obstante, la situación se repite años más tarde, ya bajo el reinado de Alfonso VI, cuando en el año 1080 Diego, abad de Sahagún, enfrentado con los hijos de Gonzalo Fernández, se presenta de nuevo en el lugar ante el monarca ${ }^{94}$.

\subsection{Reestructuración administrativo-territorial: la respuesta regia}

Quizás la característica más notable de este nuevo modelo de organización al que venimos haciendo referencia sea la naturaleza temporal y revocable de estos cargos administrativos ${ }^{95}$, lo que va a favorecer la movilidad de los funcionarios regios evitando de este modo la asimilación de ciertos personajes con ciertos distritos territoriales y sus centros de control y articulación ${ }^{96}$. Tales disposiciones no van a evitar, sin embargo, que estos nom-

\footnotetext{
${ }^{91}$ Véase Vital 2012.

${ }_{92}$ Un estudio muy interesante sobre estas cuestiones es el propuesto por Escalona 2004, pp. 101-152.

${ }^{93}$ CDMS-II, doc. 588.

${ }^{94}$ Alfonso VI, doc. 69.

${ }_{95}$ Para autores como Álvarez Borge las tenencias deben contemplarse como cargos de carácter temporal, no feudal en sentido jurídico, pero no dependientes de forma exclusiva de la voluntad regia. Álvarez 2008, p. 242.

${ }^{96}$ Baste citar las referencias que a comienzos del siglo XII encontramos en relación a los cargos ejercidos en Castro Froila-Mayorga. Así, en el año 1102, se documenta a "Ero Gutterriz in Castro Froila". (CDMS-III, doc. 1080); en ese mismo año se constata como "maiorino maiore"
} 
bramientos sigan recayendo sobre personalidades representativas, miembros integrantes de la alta nobleza que habían desempeñado durante la etapa precedente importantes cargos políticos o habían asumido la dignidad condal ${ }^{97}$, si bien se observa asimismo el avance y progresiva implicación en estos asuntos de nobles que podemos considerar de segunda categoría, en un intento de frenar el posicionamiento de los grandes linajes ${ }^{98}$. Esta pretensión parece haber resultado, no obstante, más teórica que práctica y en este sentido la revisión documental permite adivinar la progresiva evolución experimentada por este modo de articulación caracterizado no sólo por su paulatina complejidad ${ }^{99}$, sino también por la lenta acumulación de bienes patrimoniales y unidades administrativas en manos de ciertas familias aristocráticas. Tenemos constancia de que en el año 1117 figura Fernando Fernández ocupando las tenencias in Malgrado et in Bolanios ${ }^{100}$, Osorio Martínez se documenta en 1141 como tenente en Malgrado et Ribera et Villa Maiore ${ }^{101}$, en 1147 el conde Pontius, mandante Villalupos et Malgrate ${ }^{102}$, Fernando Rodríguez ejercerá las tenencia en Malgrad, Coyanza y Mayorga ${ }^{103}$ y en el año 1188 lo hará el conde Fernando Núñez de Lara como tenens Venaventum et Zamoram ${ }^{104}$.

De forma paralela al desarrollo de todos estos acontecimientos y estrechamente vinculadas a ellos, nos interesa destacar las transformaciones que se están generando a nivel territorial, los cambios que hasta el momento viene experimentando el espacio objeto de estudio a la luz de los acontecimientos políticos y socio-económicos y el modo en el que todas estas modificaciones se plasman y evidencian en el mismo. Ya se ha hecho alusión al debilitamiento que comienzan a sufrir algunos de estos centros castrales, ejes de articulación territorial al menos hasta el siglo $\mathrm{X}$, reemplazados en sus funciones por centros próximos -como sucedería con Castro Abaiub-. En otros casos comienzan a dar origen, a los pies del antiguo castro, a una nueva célula de población, como sucedería en el caso de Val de Heras ${ }^{105}$, adoseira Sancti Micahelis, sub

a Pelaio Xapiz. (CDMS-III, doc. 1082); en 1107, tenemos noticia de "Maiorinus in Castro Froila et in Legione Michael Afonsu". (CDMS-III, doc. 1158). Mínguez 2007b, pp. 61-65.

97 "comite Alfonso tenente Bergido et Iorres", Jular 1990, p. 111. "Comes (Rode)rigus in Aguilar et in Vezela". (CDMG-I, doc. 36).

${ }^{98}$ En relación a estas cuestiones y para profundizar en su comprensión, remitimos a la ya citada obra de Vital 2012, pp. 203-204.

${ }^{99}$ Jular 1990, pp. 111-113.

${ }^{100}$ Ayala 1995, doc, 9.

${ }^{101}$ Ibidem, doc. 48.

102 Ibidem, doc. 53.

${ }^{103}$ Monsalvo 2002, pp. 48-49.

${ }^{104}$ CDCA-II. doc. 889.

${ }^{105}$ Al parecer Valderas es citado por primera vez en el año 1120. Martínez 1985, p. 66. 
Kastro Macarefe. Este castro que será además reemplazado por el castillo plenomedieval del que no parece conservarse resto alguno posiblemente por estar realizado con tapial pero del que tenemos constancia documental a través de la alusión a la iglesia de Santa María que est fundata in Castello de Valdeiras ${ }^{106}$. A un destino similar se verían sometidos los castros de Foracasas (Mapa 3) y Abduci, dando origen respectivamente a las entidades de Melgar de Arriba y Melgar de $\mathrm{Abajo}^{107} \mathrm{o}$ Mayorga, uno de los centros más importantes de la ribera del Cea, surgido a partir de Castro Froila. Este último se cita como tal todavía en el año 1107, como se desprende de un documento por el que sabemos de la presencia de un merino en el lugar en ese mismo año ${ }^{108}$. Más adelante, en 1127, será el topónimo de Mayorga el que conste documentalmente ${ }^{109}$ comenzando a cobrar pujanza y reemplazando al castro próximo en el desempeño de las funciones políticas, urbanas y territoriales ${ }^{110}$. Ya bajo el reinado de Fernando II, Mayorga concentrará las funciones militares y políticas ${ }^{111}$, iniciándose la "repoblación" de la villa en el año 1181 y recibiendo carta foral ${ }^{112}$.

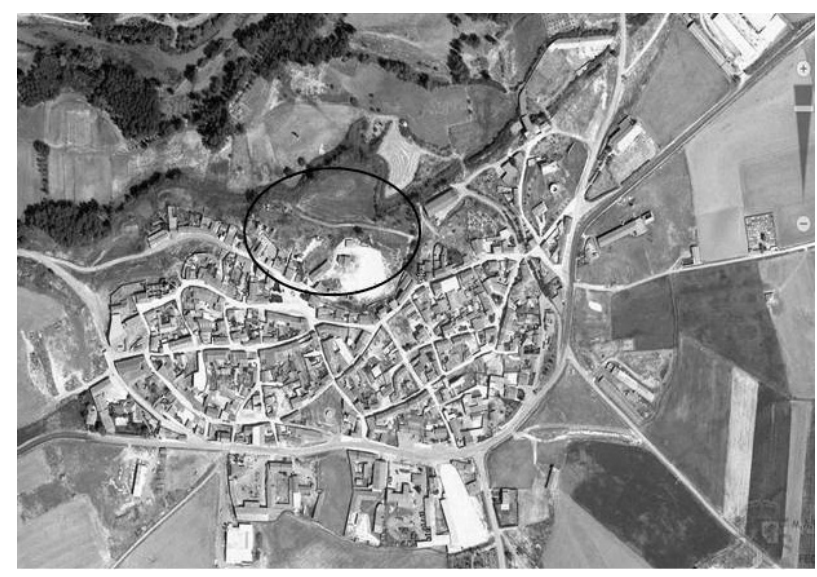

Mapa 3. Emplazamiento del centro fortificado en Melgar de Arriba.

\footnotetext{
${ }^{106}$ Sus tenentes son además conocidos desde el año 1129. Gutiérrez 1995, p. 309.

${ }^{107}$ En estos centros se documentan tenentes y merinos a principios del siglo XII. Este sería el caso, en 1113, del "Comite don Petrus in Saldania et in Melgare" (CDMS-IV, doc. 1187).

108 "Maiorinus in Castro Froila et in Legione Michael Afonsu" (CDMS-III, doc. 1158).

109 "Petrus Lupiz in Maiorice urbe...", (CDMV, n n 37) Según especifica Martínez Sopena, Castro Froila deja de documentarse en torno al año 1130, al mismo tiempo que Mayorga comienza a hacerlo hacia 1127, conformando de este modo un claro ejemplo de sustitución. Véase Martínez 1985,p. 141.

${ }^{110}$ Gutiérrez 1995, p. 341.

${ }^{111}$ Ibidem, p. 338.

${ }^{112}$ Rodríguez 1968, p. 318.
} 
A la luz de tales hechos, se observa la sustitución de los antiguos centros castreños vigentes durante la etapa precedente por nuevos núcleos surgidos al calor de los cambios políticos, sociales y económicos que vienen operando al menos desde mediados del siglo XI y que, como vemos, tienen su plasmación en el territorio bajo nuevas fórmulas administrativas.

\subsection{Castros y castillos: el papel de los núcleos fortificados}

Llegados a este punto cabría preguntarse cuál fue el papel desempeñado por estos centros fortificados, castros y castillos, y su evolución a lo largo del periodo alto y plenomedieval. Parece haber quedado claro, a lo largo de las páginas precedentes, que estas unidades políticas que se dibujan en el valle del Cea y las células de población que en ellas se insertaban, aparecían controladas o reguladas por centros desde los que se llevaba a cabo la articulación y gestión de sus recursos materiales y humanos. Los castros desempeñaron por tanto una importante función en el proceso de integración territorial en el programa político gestado por la monarquía astur-leonesa.

Junto a la obra de Gutiérrez González, citada en diversas ocasiones, destacan las interesantes aportaciones efectuadas por Vázquez Álvarez para el sector comprendido entre el Arlanza y el Duero ${ }^{113}$. Para el autor, son dos los mecanismos de actuación que dieron origen a muchos de los centros fortificados erigidos en su ámbito de estudio entre el siglo X y principios del XI. El primero partiría de una iniciativa privada, lo que le lleva a considerar estos elementos como núcleos de encuadramiento y control feudal, fijación y concentración del hábitat. Si bien, junto a éstos, se hallarían aquéllos que parten de la iniciativa pública, destacando por su carácter estratégico y militar y su papel como cabeceras territoriales ${ }^{114}$. Por su parte, y desde finales de ese siglo XI, se contempla el surgimiento y desarrollo de nuevos núcleos urbanos encaminados a la redistribución del poder y la gestación de alianzas favorables en el poder central y las aristocracias ${ }^{115}$. Todos estos planteamientos deben completarse, sin embargo, con el análisis que para los territorios catalanes realiza Batet i Company para quien los castells termenats han de estudiarse y valorarse desde su vinculación al ejercicio del control por parte de un determinado poder, actuando como células territoriales básicas ${ }^{116}$. En tal sentido, la conformación de la red castral respondería en este caso concreto a un

\footnotetext{
${ }^{113}$ Vázquez 1999, pp. 351-374.

${ }^{114}$ Ibidem, pp. 357-368.

${ }^{115}$ Ibidem, p. 368.

${ }^{116}$ Batet 1996, pp. 52-54.
} 
programa político concreto fundamentado en la expansión territorial encabezada por los poderes condales ${ }^{117}$. En definitiva, y en función de la información proporcionada por la autora, se puede colegir, para el caso catalán, una mayor aproximación a los planteamientos que se observan en Italia a través de la configuración de extensas e importantes unidades patrimoniales que toman como eje central la titularidad del castell termenat ${ }^{118}$. Esta situación se explicaría por un hecho que en nuestro caso reviste un interés fundamental, que no es otro que desde finales del siglo $\mathrm{X}$ la titularidad de los castillos deja de estar en manos del conde para pasar a manos de diversos linajes nobiliarios ${ }^{119}$. A la luz de tales consideraciones podemos preguntarnos qué es lo que sucede en Tierra de Campos y cuál es el papel desempeñado aquí por estas células tras haberse consolidado la integración en el proyecto político promovido por la monarquía. Y es que, tal y como venimos apuntando, en el grado de implicación y actuación por parte de ésta reside buena parte de las diferencias que podemos discernir en relación al patrón italiano y el sector este peninsular. Las citadas referencias a Castro Froila y la presencia del rey en el lugar dan cuenta de la función asumida por este centro como sede de poder político ${ }^{120}$, si bien a estos documentos cabría incorporar aquéllos que dejan constancia del pleito que en el año 1082 mantienen el abad de Samos y el vicario del rey ${ }^{121}$, o el que en 1091 enfrenta al abad de Sahagún y los habitantes de Villavicencio ${ }^{122}$.

Por otro lado, aunque la militar o estratégica no fuese la única causa del origen de muchos de estos centros, tampoco podemos perder de vista el ambiente político en el que algunos de estos emplazamientos se vieron inmersos durante el siglo XII. El motivo de estos conflictos hay que buscarlo en la división del reino tras la muerte de Alfonso VII, hecho que incentivó la rivalidad y enfrentamiento entre sus herederos, Fernando II de León y Sancho III de Castilla, primero, y de Alfonso VIII más tarde. Una de las consecuencias de este tenso panorama fue la puesta en marcha de una serie de actuaciones encaminadas a la reutilización y refortificación de algunos de estos centros donde aún hoy en día resultan visibles ciertos vestigios atribuibles a antiguas fortalezas, testimonios materiales del pasado de estos lugares ${ }^{123}$. Al margen de estas funciones de carácter militar, algunos de estos castillos aca-

${ }^{117}$ Batet 1995, p. 345.

${ }^{118}$ Batet 1996, p. 55.

${ }^{119}$ Ibidem, p. 57.

${ }^{120}$ Mínguez 2007b, pp. 56-57.

121 "Sic levavit se dominus Formaricus Abbas, et fratres sui V, et ipse Eita Gosendiz, et pergerunt pro ad illum regem, et invenerunt eum in Castro Froila". Alfonso VI, doc. 75.

122 "in voce de homines supradictos, contra abbatem supra taxatum in assercione et comtemptione ante regem dominum Adefonsum in Castro Froila". Ibidem, doc. 115.

${ }^{123}$ Sobre Melgar de Arriba véase Gutiérrez 1995, p. 344. 
barán por convertirse en prendas destinadas a garantizar el cumplimiento y respeto de la diversidad de pactos y tratados habidos entre los reyes de León y Castilla lo que, en última instancia, vendría a explicar el destino de lugares como Valderas o el propio Melgar ${ }^{124}$. La lectura que debemos hacer de estos hechos es, sin embargo, más profunda en tanto que la concesión de estos centros por parte de la monarquía y el cambio de titularidad al que se vieron sometidos revela que, en realidad, era el rey -castellano o leonés- quien ejercía el dominio sobre ellos, ya fuese de forma directa, a través del nombramiento de tenentes y merinos o por medio de la creación de villas reales y dotaciones forales, siempre en un intento de limitar la expansión de los señoríos laicos y eclesiásticos ${ }^{125}$.

\section{CONCLUSIONES}

Iniciábamos nuestro estudio aludiendo al incastellamento y a la relevancia alcanzada por éste a la hora de explicar el desarrollo del Occidente medieval. Señalábamos que nuestra intención no era, en este caso, verificar o, por el contrario, desmentir su presencia en la Península, sino profundizar en el análisis de aspectos que, entendemos, pueden resultar de especial interés de cara a incentivar el debate en torno al feudalismo. En este sentido, las divergencias y semejanzas que hemos podido observar entre las región de la Toscana y la Tierra de Campos -en el cuadrante noroeste peninsular- en relación al papel desempeñado por los castillos y el tipo de vínculo entre poderes, pueden contribuir a su comprensión y ayudarnos a perfilar las vías de gestación y configuración en ambas zonas en función de contextos políticos, sociales y económicos diversos y específicos en cada caso.

En lo que se refiere al rol ejercido por las fortificaciones sí es posible constatar en el caso italiano, y de forma relativamente temprana, la participación de entes señoriales -laicos y eclesiásticos-en la fundación de este tipo de construcciones, tal sería el caso del obispo Pietro II a quien ha de atribuirse la creación de los castillos de Santa Maria a Monte, Moriano o Pietrabuona, entre otros. Por su parte, y partiendo de un alto grado de heterogeneidad, el mapa de distribución señorial perfilado por Wickham ha revelado el extenso control alcanzado por ciertas parentelas, especialmente en el sur de la Toscana, donde

\footnotetext{
${ }^{124}$ Ambos pasarán en el siglo XII a manos castellanas. Luis 2003, pp. 150 y 160.

${ }^{125}$ En este sentido, Alfonso VII centraría su atención fundamentalmente en Mayorga, Valderas, Bolaños, Villafrechós, Villalpando, Villagarcía, Pajares y Villacete, participando asimismo su hermana, la infanta Doña Sancha en el control de Medina de Rioseco, Villabrágima, Urueña y Castromonte. Véase Luis 2003, pp. 144-145.
} 
la presencia de otros poderes - por ejemplo la ciudad- fue menos acusada, favoreciendo de este modo la autonomía e independencia de linajes como el de los Aldobrandeschi o Gerardeschi.

Esta representación señorial se haría efectiva a través del castillo, poderoso elemento -asimismo- de control y dominio socio-económico tal y como revelan, por ejemplo, los datos derivados de Rocca San Silvestro. Pero esta situación de difusión y fortalecimiento señorial cabría explicarse, además, por lo que parece traducirse en una escasa presencia del poder central en la gestión de organización y administración territorial. Un escaso intervencionismo que contrasta, de hecho, con la situación que hallamos en Tierra de Campos, donde los señores vieron limitadas sus pretensiones expansivas a través de la actuación emprendida por la monarquía cuya presencia territorial se mostraría desde un principio más activa. En este sentido, los castros desempeñaron inicialmente un importante papel como elementos centrales en la articulación del valle del Cea y la jerarquización del poblamiento y de la red aldeana que se iría gestando en su seno. En este contexto de expansión hacia el sur, la monarquía haría efectiva su participación a través de la delegación de funciones administrativas en grandes propietarios de la zona, en algunos casos muy próximo al propio entorno regio, como hemos tenido ocasión de comprobar con Foracasas iben Tajon, encargado de repoblar y articular la zona a partir del castro del Melgar, documentado desde el año 945 como Melgar de Foracasas y centro de control y jerarquización del territorio circundante.

La progresiva y cada vez mayor acumulación de bienes, propiedades y derechos de inmunidad en manos de ciertos grupos de poder derivó en una serie de enfrentamientos y renegociaciones que hemos de entender, sin embargo, en el propio contexto de señorialización y feudalización al que se estaba viendo sometida la sociedad. Hechos que han de explicarse además valorando las necesarias relaciones establecidas entre el rey y los señores, imprescindibles desde ambos puntos de vista para garantizar el estatus y posicionamiento de ambos poderes.

Dicha situación experimenta cierto giro con el advenimiento de la dinastía navarra y la formulación y adopción, por parte de la monarquía, de una serie de medidas y mecanismos favorecidos por las condiciones políticas del momento, y encaminadas a poner freno al expansionismo y fortalecimiento señoriales. Comienza a hacerse efectivo el nombramiento de ciertos cargos -tenentes y merinos- cuya principal característica viene a ser el carácter temporal y revocable de sus funciones.

La monarquía no dejó de estar presente en la zona ya fuese de forma directa o a través de sus delegados, careciendo además de datos que nos permitan concluir para este sector la fundación de elementos fortificados por iniciativa señorial como ha sido posible comprobar en la Toscana. Ello no 
descarta, sin embargo, la posibilidad de observar cierta aproximación a estas medidas de actuación en otros sectores, como deparan los estudios realizados por Vázquez para la franja comprendida entre el Arlanza y el Duero y, desde luego, de manera más acusada en los condados catalanes, donde la titularidad de estas fortificaciones parece acabar en manos de ciertas familias aristocráticas. Diferencias claras, por tanto, en relación a la participación del poder central, más intensa y acusada en el sector peninsular que en la franja italiana. Pretensiones expansionistas por parte de los señores en ambas zonas, que parecen cuajar y consolidar en Italia a través de la acumulación de amplios bienes patrimoniales visibles sobre todo en el sur de la región, y limitarse en Tierra de Campos gracias a las medidas adoptadas por la autoridad central. Castillos que, al margen de un interés militar y estratégico que no debemos obviar, actúan como centros de control y dominio de los recursos sociales y humanos insertos en su territorio, y sedes de poder y representación: de ciertas familias toscanas, cuya titularidad ostentan, y de la monarquía castellanoleonesa.

\section{BIBLIOGRAFÍA CITADA}

Álvarez Borge, Ignacio (2008), Cambios y alianzas. La política regia en la frontera del Ebro en el reinado de Alfonso VIII de Castilla (11581214), Madrid, Consejo Superior de Investigaciones Científicas.

Andenna, Giancarlo (1996), Formazione, strutture e processi di riconoscimento giuridico delle signorie rurali tra Lombardia e Piemonte orientale (secoli X-XIII), en Dilcher, Gerhard; Violante, Cinzio, Strutture e trasformazioni della signoria rurale nei secoli X-XIII. Atti della XXXVII settimana di studio, 12-16 settembre 1994, Bolonia, Il Mulino, pp. 123-167.

Arranz Mínguez, Jesús Álvaro; Gómez Pérez, Alicia; Parrado Cuesta, María Soledad (1991-1992), El yacimiento romano-medieval de La Ermita en Melgar de Arriba, "Numantia. Arqueología en Castilla y León" 5, pp. 127-138.

Augenti, Andrea (2000a), Dai castra tardoantichi ai castelli del secolo X: il caso della Toscana, en Francovich, Riccardo; Ginatempo, Maria (eds.), Castelli, storia e archeologia del potere nella Toscana medievale, Florencia, All'Insegna del Giglio, vol. I, pp. 25-66.

Augenti, Andrea (2000b), Un territorio in movimento. La diocesi di Volterra nei secoli X-XII, en Francovich, Riccardo; Ginatempo, Maria (eds.), Castelli, storia e archeologia del potere nella Toscana medievale, Florencia, All'Insegna del Giglio, vol. I, pp. 111-139. 
Ayala Martínez, Carlos de (ed.) (1995), Libro de privilegios de la Orden de San Juan de Jerusalén en Castilla y León. (Siglos XII-XV), Madrid, Instituto Complutense de la Orden de Malta.

Batet i Company, Carolina (1995), La Marca encastellada? Castells i pautes d'assentament a la Marca del comtat de Barcelona (segles X-XI), “Afers” 21, pp. 341-360.

Batet i Company, Carolina (1996), Castells termenats i estratègies d'expansió comtal: la Marca de Barcelona als segles X-XI, Barcelona, Institut d'Estudis Penedesencs.

Benente, Fabrizio (2000), L'incastellamento in Liguria. Bilancio e destini di un tema storigrafico, en Benente, Fabrizio, L'incastellamento in Liguria. X-XII secolo. Bilancio e destini di un tema storiografico, Bordighera, Istituto internazionale di studi Liguri, pp. 17-69.

Blanco Lozano, Pilar (1986), Colección diplomática de Fernando I (10371065), "Archivos leoneses" 79-80, pp. 7-212.

Brogiolo, Gian Pietro; Chavarría, Alexandra (2005), Aristocrazie e campagne nell'Occidente da Costantino a Carlo Magno, Florencia, All'Insegna del Giglio.

Burón Castro, Taurino (1998), Colección documental del Monasterio de Gradefes. Vol. I, León, Centro de Estudios e Investigación San Isidoro.

Cagnana, Aurora; Gardini, Alexandre; Vignola, Marco (2010), Castelli e territorio nella repubblica di Genova (secoli X-XIII). Un confronto tra fonti scritte e strutture materiali, "Archeologia medievale" 37, pp. 29-46.

Carocci, Sandro (2001), Señorío italiano, señorío del Lazio, comunidades rurales, en Álvarez Borge, Ignacio (ed.), Comunidades locales y poderes feudales en la Edad Media, Logroño, Universidad de la Rioja, pp. 67-90.

Carocci, Sandro (2007), Le lexique du prélèvement seigneurial: note sur les sources italiennes, en Bourin, Monique; Martínez Sopena, Pascual (eds.), Pour une anthropologie du prélèvement seigneurial dans les campagnes médiévales (XIe-XIVe siècles). Les mots, les temps, les lieux, París, Publications de la Sorbone, pp. 137-157.

Carrera de la Red,Fátima (1988), Toponimia de los valles del Cea, Valderaduey y Sequillo, León, Institución Fray Bernardino de Sahagún.

Carvajal Castro, Álvaro; Martín Viso, Iñaki (2013), Historias regionales de la repoblación: los reyes asturleoneses y las políticas de la tierra en el oeste de la meseta del Duero, en Díaz, Pablo de la Cruz; Luis Corral, Fernando; Martín Viso, Iñaki (eds.), El historiador y la sociedad. Homenaje al profesor José María Mínguez, Salamanca, Universidad de Salamanca, pp. 39-52. 
Cavero Domínguez, Gregoria; Martín López, Encarnación (1999), Colección documental del Archivo de la Catedral de Astorga. Vol.I (646-1126), León, Centro de Estudios e Investigación San Isidoro.

Cavero Domínguez, Gregoria; Martín López, Encarnación (2000), Colección documental del Archivo de la Catedral de Astorga. Vol. II (11261299), León, Centro de Estudios e Investigación San Isidoro.

Cortese, Maria Elena (2000a), L'incastellamento nel territorio di Arezzo (secoli X-XII), en Francovich, Riccardo; Ginatempo, Maria (eds.), Castelli, storia e archeologia del potere nella Toscana medievale, Florencia, All'Insegna del Giglio, vol. I, pp. 67-110.

Cortese, Maria Elena (2000b), Castelli e città: l'incastellamento nelle aree periurbane de la Toscana, en Francovich, Riccardo; Ginatempo, Maria (eds.), Castelli, storia e archeologia del potere nella Toscana medievale, Florencia, All'Insegna del Giglio, vol. I, pp. 205-237.

Cucini, Costanza (1989), Le dinamiche insediative nella Toscana en Francovich, Riccardo; Cucini, Costanza; Parenti, Roberto, Dalla villa al castello: dinamiche insediative e tecniche costruttive in Toscana fra tardoantico e bassomedioevo "Archeologia Medievale" 16, pp. 49-56.

Domínguez Sánchez, Santiago (2001), Colección documental medieval de los monasterios de San Claudio de León, Monasterio de Vega y San Pedro de las Dueñas, León, Centro de Estudios e Investigación San Isidoro.

Escalona Monge, Julio (2001), Unidades territoriales supralocales: una propuesta sobre el origen del señorío de behetrías, en Estepa Díaz, Carlos; Jular Pérez-Alfaro, Cristina (coords.), Los señoríos de behetría, Madrid, Consejo Superior de Investigaciones Científicas, pp. 21-46.

Escalona Monge, Julio (2002), Sociedad y territorio en la Alta Edad Media Castellana: la formación del alfoz de Lara, Oxford, British Archaeological Reports (BAR International Series; 1079).

Escalona Monge, Julio (2004), Misericordia regia, es decir, negociemos. Alfonso VII y los Lara en la Chronica Adefonsi Imperatoris, en Alfonso, Isabel; Escalona, Julio; Martin, George (coords.), Lucha política. Condena y legitimación en la España medieval, Lyon, ENS Éditions, pp. 101-152.

Estepa Díez, Carlos (2006), Sobre los orígenes de los merinos mayores en León y Castilla, en Mínguez Fernández, José María; Del Ser Quijano, Gregorio (coord.), La Península en la Edad Media: treinta años después. Estudios dedicados a José Luis Martín, Salamanca, Universidad de Salamanca, pp. 87-100. 
Farinelli, Roberto; Francovich, Riccardo (1994), Potere e attività minerarie nella Toscana altomedievale, en Francovich, Riccardo; Noye, Ghislaine (eds.), La Storia dell'alto Medievo italiano (VI-X secolo) alla luce dell'archeologia, Florencia, All'Insegna del Giglio, pp. 443-465.

Farinelli, Roberto; Giorgi, Andrea (2000), Fenomeni di acentramento insediativo nella Toscana meridionale tra XII e XIII secolo. Il secondo incastellamento in area senese, en Francovich, Riccardo; Ginatempo, Maria (eds.), Castelli, storia e archeologia del potere nella Toscana medievale, Florencia, All'Insegna del Giglio, vol. I, pp. 239-284.

Fernández Flórez, José Antonio (1991), Colección diplomática del Monasterio de Sahagún (857-1300). Vol. IV (1100-1199), León, Centro de Estudios e Investigación San Isidoro.

Francovich, Riccardo; Bianchi, Giovanna (2002), L'archeologia dell'elevato come archeologia, "Arqueología de la arquitectura" 1, pp. 101-111.

Francovich, Riccardo; Cucini, Cristina; Parenti, Roberto (1989), Dalla villa al castello: dinamiche insediative e tecniche costruttive in Toscana fra tardoantico e bassomedioevo, "Archeologia Medievale" 16, pp. 47-78.

Francovich, Riccardo; Ginatempo, Maria (2000), Introduzione, en Francovich, Riccardo; Ginatempo, Maria (eds.), Castelli, storie e archeologia del potere nella Toscana medieval, Florencia, All'Insegna del Giglio, pp. 7-24.

Francovich, Riccardo; Wickham, Chris (1994), Uno scavo archeologico ed il problema dello sviluppo della signoria territoriale: Rocca San Silvestro e i rapporti di produzione minerali, "Archeologia medievale" 21 , pp. 7-30.

Frondoni, Alessandra; Benente, Fabrizio; Garibaldi, Tiziana (2000), Lo scavo del castello di Rivarda. Notizia preliminari sulle campagne di scavo 1996/97, en L'incastellamento in Liguria: X-XII secolo. Bilancio e destini di un tema storiografico, Bordighera, Istituto Internazionale di Studi Liguri, pp. 181-216.

Fumagalli, Vito (1974), Terra e società nell'Italia Padana. I secoli IX e X, Bolonia, Università degli Studi di Bologna, Istituti di Storia medievale e moderna e di Paleografia e Diplomatica.

Fumagalli, Vito (1978), Coloni e signori nell'Italia settentrionale. Secoli VI-XI, Bolonia, Pàtron.

Fumagalli, Vito (1984), Introducción del feudalismo y desarrollo de la economía curtense en la Italia septentrional, en Estructuras feudales y feudalismo en el mundo mediterráneo (siglos X-XIII), Barcelona, Crítica, pp. 200-214.

Gambra, Andrés (1998), Alfonso VI. Cancillería, curia e imperio. Vol II. Colección diplomática, León, Centro de Estudios e Investigación San Isidoro. 
García Larragueta, Santos Agustín (1962), Colección de documentos de la catedral de Oviedo, Oviedo, Diputación de Asturias - Instituto de Estudios Asturianos - Patronato José $\mathrm{M}^{\mathrm{a}}$ Quadrado - CSIC.

Gutiérrez González, José Avelino (1995), Fortificaciones y feudalismo: en el origen y formación del reino leonés (siglos IX-XIII), Valladolid, Universidad de Valladolid.

Herrero de la Fuente, Marta (1988), Colección diplomática del Monasterio de Sahagún (857-1230). Vol. II (1000-1073), León, Centro de Estudios e Investigación San Isidoro.

Herrero de la Fuente, Marta (1988), Colección diplomática del Monasterio de Sahagún (857-1230). Vol. III (1073-1109), León, Centro de Estudios e Investigación San Isidoro.

Jular Pérez-Alfaro, Cristina (1990), Los Adelantados y Merinos mayores de León (siglos XIII-XV), León, Universidad de León.

Luis Corral, Fernando (2003), Villavicencio en la Edad Media. Propiedad y jurisdicción en los valles del Cea y del Valderaduey, Valladolid, Diputación provincial de Valladolid.

Martín Viso, Iñaki (2000), Poblamiento y estructuras sociales en el norte de la Península Ibérica (siglos VI-XIII), Salamanca, Universidad de Salamanca.

Martín Viso, Iñaki (2001), Riflessioni sull'incastellamento nella Penisola Ibérica: la Castiglia dell'Ebro e la Transierra di Madrid, "Archeologia medievale" 28, pp. 83-110.

Martín Viso, Iñaki (2012), La monarquía asturleonesa en el Bierzo (siglo IX$X$ ), en Mundos medievales: espacios, sociedades y poder. Homenaje al profesor José Ángel García de Cortázar y Ruiz de Aguirre, Santander, Universidad de Cantabria, pp. 733-746.

Martínez Sopena, Pascual (1985), La Tierra de Campos occidental. Poblamiento, poder y comunidad del siglo X al XII, Valladolid, Institución cultural Simancas.

Martínez Sopena, Pascual (2007), Territorio y sociedad en León durante el reinado de Fernando I, en González Fernández, Etelvina; Pérez Gil, Javier (coord.), Alfonso VI y su época I. Los precedentes del reinado (966-1065). Sahagún, 4-7 de septiembre de 2006, León, Universidad de León, pp. 121-145.

Mínguez Fernández, José María (1976), Colección diplomática del Monasterio de Sahagún (siglos IX-X), León, Centro de Estudios e Investigación San Isidoro.

Mínguez Fernández, José María (1998), El incastellamento, veinte años después,en Barceló,Miquel; Toubert,Pierre (coords.),L'incastellamento: actas de las reuniones de Girona y de Roma, Roma, École française de Rome, pp. 7-12. 
Mínguez Fernández, José María (2007a), Contexto social y político-militar del reino de León al advenimiento de la dinastía navarra, en Fernández González, Etelvina; Pérez Gil, Javier (coords.), Alfonso VI y su época I. Los precedentes del reinado (966-1065). Sahagún, 4-7 de septiembre de 2006, León, Universidad de León, pp. 17-35.

Mínguez Fernández, José María (2007b), Pervivencia y transformación de la concepción y práctica del poder en el reino de León (siglos X-XI), "Studia Historica. Historia Medieval” 25, pp. 15-65.

Mínguez Fernández, José María (2009), Poderes locales en el espacio central leonés durante el periodo astur, en Fernández, Javier; García de Castro, César (eds.), Poder y simbología en Europa, siglos VIII-X. Actas del Symposium internacional, Oviedo, 22-27 de septiembre 2008, Gijón, Ediciones Trea, pp. 199-214 (Territorio, Sociedad y Poder. Anexos; 2).

Monsalvo Antón, José María (2002), De los alfoces regios al realengo concejil en el reino de León (1157-1230). La territorialidad de las ciudades y las villas reales entre la Cordillera Cantábrica y el Duero, en El reino de León en la época de las cortes de Benavente. Jornadas de Estudios Históricos, Benavente, Centro de Estudios Benaventanos "Ledo del Pozo", pp. 29-100.

Morsel, Joseph (2008), La aristocracia medieval. El dominio social en Occidente (siglos $V-X V$ ), Valencia, Publicacions de la Universitat de València.

Nardini, Alessandra (1999), L'incastellamento nel territorio di Chiusdino (Siena) tra X e XI secolo. I casi di Miranduolo e Serena, "Archeologia medievale" 26, pp. 339-351.

Nuccioti, Michele, Leporatti, Silvia (2003), Organizzazione del cantiere di una fortezza rurale di XIII secolo: il cassero di Montelaterone (Monte Amiata- Toscana), "Arqueología de la Arquitectura" 2, pp. 255-265.

Parenti, Roberto (1989), Tecniche costruttive delle abitazioni medievali, in margine alle esperienze toscane, Francovich, Riccardo; Cucini, Costanza; Parenti, Roberto, Dalla villa al castello: dinamiche insediative e tecniche costruttive in Toscana fra tardoantico e bassomedioevo, "Archeologia Medievale" 16, pp. 47-78.

Quirós Castillo, José Antonio (1999), El incastellamento en el territorio de la ciudad de Luca (Toscana). Poder y territorio entre la Alta Edad Media y el siglo XII, Oxford, British Archaeological Reports (BAR International Series; 811).

Quirós Castillo, José Antonio (2011), L'eccezione che conferma la regola? Incastellamento nella valle dell'Ebro nel $X$ secolo: il castello di Treviño, "Archeologia medievale" 38, pp. 113-136. 
Quirós Castillo, José Antonio (2012), Los castillos altomedievales del cuadrante noroccidental de la Península Ibérica, en Quirós Castillo, José Antonio; Tejado Sebastián, José María (eds.), Los castillos altomedievales en el noroeste de la Península Ibérica, Bilbao, Universidad del País Vasco, pp. 17-27.

Rodríguez Fernández, Justiniano (1968), Apuntes para la historia de Mayorga, "Archivos Leoneses" 44, pp. 273-372.

Rodríguez Fernández, Justiniano (1982), Los Reyes de León. Ordeño III, Madrid, Ediciones leonesas.

Rodríguez Fernández, José Luis (2007), Melgar de Arriba. Historia de una villa de Tierra de Campos desde los inicios hasta principios del siglo XVI, Valladolid, Diputación de Valladolid.

Ruiz Asencio, José Manuel (1987), Colección documental del Archivo de la Catedral de León (775-120). Vol. III (986-1031), León, Centro de Estudios e Investigación San Isidoro.

Ruiz Asencio, José Manuel; Ruiz Albi, Irene (2007), Colección documental del Monasterio de San Pedro de Eslonza. Vol. I (912-1300), León, Centro de Estudios de Investigación San Isidoro.

San Miguel Mate, Luis Carlos (1995), Notas sobre la secuencia y características arqueológicas del yacimiento de la Edad de Hierro de Melgar de Abajo (Valladolid), en Delibes de Castro, Germán; Escudero Navarro, Zoa; Romero Carnicero, Fernando; Morales Muñiz, Arturo (coords.), Arqueología y medio ambiente. El Primer milenio a.C. en el Duero Medio, Valladolid, Consejería de Cultura y Turismo, pp. 307-317.

Santamaría Pérez, Ricardo (2009), Factores de control del territorio en tiempos de Alfonso VI de Castilla (1065/1072-1109): el ejemplo del área riojana, "Miscelánea medieval murciana" 33, pp. 185-194.

Torres Sevilla, Margarita (1999), Linajes nobiliarios de León y Castilla. Siglos IX-XIII, Valladolid, Junta de Castilla y León.

Toubert, Pierre (1973), Les structures du Latium médiéval. Le Latium méridional et la Sabine du IXe siècle à la fin du XIIe siècle, Roma, École française de Rome.

Valenti, Marco (2004), L'insediamento altomedievale nelle campagne toscane. Paesaggi, popolamento e villaggi tra VI e X secolo, Florencia, All'Insegna del Giglio.

Valenti, Marco (2007), Aristocrazie ed élites, deboli e forti, nella Toscana tra VI e X secolo, en Brogiolo, Gian Pietro; Chavarría, Alexandra (eds.), Archeologia e società tra tardo antico e alto Medievo, $12^{\circ}$ Seminario sul tardo antico e l'alto Medioevo, Padova, 29 settembre-1 ottobre 2005, Mantova, SAP Società Archeologica, pp. 205-240. 
Varaldo, Carlo (2000), Incastellamento e popolamento nel Savonese, en L'incastellamento in Liguria. X-XII secolo. Bilancio e destini di un tema storigrafico, Bordighera, Istituto Internazionale di Studi Liguri, pp. 131-161.

Vázquez Álvarez, Roberto (1999), Castros, castillos y torres en la organización social del espacio en Castilla: el espacio del Arlanza al Duero (siglos IX al XIII), en García de Cortázar, José Ángel (coords.), Del Cantábrico al Duero. Trece estudios sobre organización social del espacio en los siglos VIII a XIII, Santander, Universidad de Cantabria, pp. 351-374.

Violante, Cinzio (1996), Introduzione: la signoria rurale nel contesto storico dei secoli X-XII, en Dilcher, Gerhard; Violante, Cinzio (eds.), Strutture e trasformazioni della signoria rurale nei secoli X-XIII, Bolonia, Il Mulino, pp. 7-57.

Vital Fernández, Sonia (2012), Reino e imperio: poder, negociación y articulación interior en época de Alfonso VII, Salamanca, Universidad de Salamanca (tesis doctoral).

Wickham, Chris (1990), Documenti scritti e archeologia per la storia dell'incastellamento: l'esempio della Toscana, en Francovich, Riccardo; Milanese, Marco. (dirs.), Lo scavo archeologico di Montarrenti e i problemi dell'incastellamento medievale. Esperienze a confronto. Atti del colloquio internazionale (Siena 1988), Florencia, All'Insegna del Giglio, pp. 79-102.

Wickham, Chris (1996), La señoría en Toscana rural, en Dilcher, Gerhard; Violante, Cinzio (eds.), Strutture e trasformazioni della signoria rurale nei secoli X-XIII, Bolonia, Il Mulino, pp. 343-409.

Wickham, Chris (1998), A che serve l'incastellemanto?, en Barceló, Miquel; Toubert, Pierre (dirs.), L'incastellamento. Actas de las reuniones de Girona y de Roma, Roma, École Française de Rome, pp. 31-42.

Wickham, Chris (2010), Archeologia e mondi rurali: quadri di insediamento e sviluppo economico, "Archeologia medievale" 37, pp. 277-284.

Fecha de recepción del artículo: septiembre 2012

Fecha de aceptación y versión final: junio 2013 